Liberty's Prisoners 


\section{EARLY AMERICAN STUDIES}

\section{Series editors:}

Daniel K. Richter, Kathleen M. Brown,

Max Cavitch, and David Waldstreicher

Exploring neglected aspects of our colonial, revolutionary, and early national history and culture, Early American Studies reinterprets familiar themes and events in fresh ways. Interdisciplinary in character, and with a special emphasis on the period from about 1600 to 1850 , the series is published in partnership with the McNeil Center for Early American Studies.

A complete list of books in the series is available from the publisher. 


\title{
Liberty's Prisoners
}

Carceral Culture in Early America

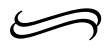 \\ Jen Manion
}

\author{
$\overline{\text { PENN }}$ \\ UNIVERSITY OF PENNSYLVANIA PRESS \\ PHILA DEL PHIA
}


Copyright (C) 2015 University of Pennsylvania Press

All rights reserved. Except for brief quotations used for purposes of review or scholarly citation, none of this book may be reproduced in any form by any means without written permission from the publisher.

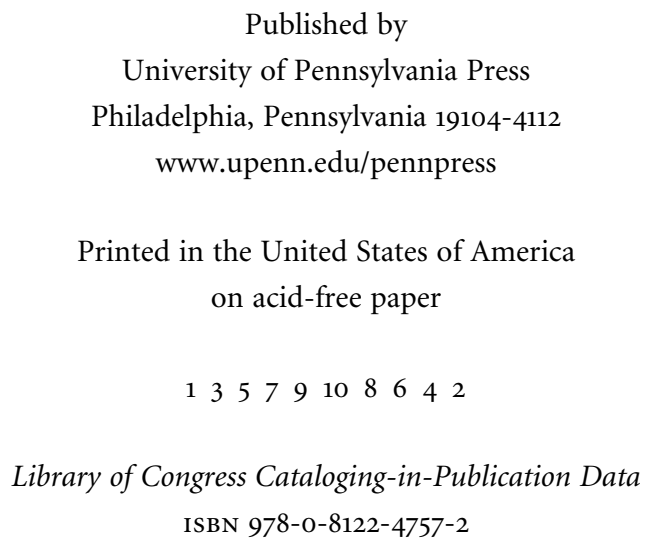


For my teachers 
This page intentionally left blank 